\title{
Anima de Wajdi Mouawad: el trauma y la violencia de la guerra en la construcción identitaria del exiliado
}

\author{
Anima by Wajdi Mouawad: the trauma and violence \\ of war in the construction of the identity of the exile
}

\author{
Marta Contreras Pérez \\ Universidad Autónoma de Madrid \\ martaconpe@gmail.com
}

\begin{abstract}
The main objective of this article is the critical study of the novel Anima by the Lebanese born and naturalised Canadian writer Wajdi Mouawad (1968-). This self-fictional work, characterized by a polyphony of animal storytellers, seduces and discomforts the reader as he or she witnesses atrocious and savage acts: rape, murder, torture and war. Each chapter brings us closer to the consequences of a linguistic, ideological, cultural and geographical exile derived from the Lebanese civil war that the author himself suffered during his childhood. Mouawad, considered a committed writer, reflects on the identity of the exile: an individual who has been a victim of loss, loneliness, violence and trauma.
\end{abstract}

\section{Keywords}

Wajdi Mouawad, identity, exile, war, trauma.

\section{Résumé}

L'objectif principal de cet article est l'étude critique du roman Anima par l'écrivain né au Liban et naturalisé canadien Wajdi Mouawad (1968-). Cet ouvrage d'autofiction, caractérisé par une polyphonie de narrateurs animaliers, séduit et incommode le lecteur qui devient témoin d'actes atroces et sauvages: viols, meurtres, tortures et guerre. Chaque chapitre nous rapproche des conséquences d'un exil linguistique, idéologique, culturel et géographique dérivé de la guerre civile libanaise que l'auteur luimême a subi pendant son enfance. Mouawad, considéré comme un écrivain engagé, réfléchit à l'identité de l'exilé: un individu qui a été victime de la perte, de la solitude, de la violence et du traumatisme.

\section{Mots-clés}

Wajdi Mouawad, identité, exile, guerre, trauma. 


\section{Introducción}

La crueldad y la violencia de la guerra siempre dejan huella en el recuerdo de aquellos que experimentan en primera persona la pérdida de sus seres queridos y de su hogar (Todorov, 1996; Morin, 1993). Como resultado, muchos son los autores obligados a exiliarse y refugiarse en un país extranjero (Arendt, 2013). Es de esta manera que la desterritorialización (Deleuze y Guattari, 1972) influye en gran medida en la construcción identitaria de los migrantes: "(la identidad) constituye el principal vínculo entre los seres humanos, sus sociedades y sus espacios. Otorgándole a la identidad, su carácter como constructo social y espacial”. (Reyes Tovar, 2011: 7). Así pues, las experiencias vividas tanto en el país de origen, como en el país de acogida condicionan y definen la identidad de este colectivo.

Este es el caso del escritor libanés Wajdi Mouawad quien nació y creció en 1968 en Beirut. Vivió la guerra civil libanesa y la llegada de refugiados palestinos a su país hasta que cumplió ocho años, cuando la situación política obligó a su familia y a él a exiliarse en Francia. Seis años más tarde, Mouawad abandonó París para vivir en Quebec durante su juventud. Finalmente, acabó instalándose en Francia donde reside actualmente. Su infancia juega un papel clave en la consolidación de su identidad. En 1977, a la edad de nueve años, es testigo de la noticia que se propagó por todo el país, a saber, el asesinato del líder druso de izquierda Kamal Youmblatt. Al igual que sus camaradas, salió a la calle para celebrar su fallecimiento: "No fue hasta los veintitantos años cuando tomé conciencia de lo que aquella celebración significaba. Me pareció una profunda injusticia, de la que encima yo era el verdugo. La voluntad de escribir surge de ese sentimiento" (Mouawad citado por Vicente, 2014: en línea).

En la actualidad, Mouawad es actor, comediante, dramaturgo, director y escritor inspirado principalmente en la tragedia griega y en autores como Stendhal, Victor Hugo y Kafka. Su éxito surgió gracias a su tetralogía Le Sang des promesses compuesta por Littoral (1999), Incendies (2003), Forêts (2006) y Ciels (2009b). A pesar de que el teatro es su principal creación literaria, Anima (2012) ha atraído la atención de innumerables lectores internacionales. Gracias a su trabajo, Mouawad se ha convertido en uno de los principales escritores de la literatura francófona contemporánea. Prueba de ello, son los numerosos galardones obtenidos como el Prix du Gouverneur général (1978), el Prix Athanase-David (1995) y el Prix Molson des Arts du Canada (2000) (Mouawad, 2009a).

Ambientada en el territorio norteamericano, Anima comienza con el horrible descubrimiento del cadáver violado de Léonie, la esposa embarazada de Wahhch Debch. La obra nos introduce a un elenco de narradores compuesto por animales, a excepción del último capítulo narrado por el forense Aubert Chagnon. La narración de estas bestias caracterizada por una prosa elegante e inocente contrasta con la brutalidad de los acontecimientos. A partir de este fatídico siniestro, el protagonista da comienzo a la persecución del asesino de Léonie. 
Wahhch Debch, un individuo traumatizado, silenciado y excluido de su realidad, emprende una odisea hasta descubrir sus auténticos orígenes libaneses ocultados por su padre adoptivo y su verdadera identidad.

Al igual que Anima, el conjunto de la obra de Mouawad se caracteriza por tópicos "como la odisea del retorno al país de origen, la busca de identidad, la irreversibilidad del tiempo, los desgarros dolorosos de la guerra y el exilio en el mundo contemporáneo, la memoria [y] el olvido" (Blarduni, 2015: 22). El lector conocedor de la biografía del autor percibe al instante los rasgos que caracterizan a Wahhch Debch y que reflejan los recuerdos y la vida de Mouawad. Ambos comparten una vida de exilio en un país extranjero con una lengua y cultura distintas:

Este es el laboratorio en el que me ha metido la vida, el del exilio, la guerra, las lenguas que no son tuyas. El exilio ha sido un lugar de un sufrimiento atroz, pero también paradójico. Me rompió en dos y, a la vez, me salvó la vida [...] Gracias a él, escapé a los círculos viciosos en los que fui criado. (Mouawad citado por Vicente, 2014: en línea)

Desde el comienzo de la novela el lector es testigo de la violencia verbal, física y psicológica que impregna Anima: los homicidios y torturas de la familia del protagonista; las violaciones de Léonie, Wahhch Debch y su hermana; las masacres de Sabra y Chatila; la Guerra Civil de los Estados Unidos y del Líbano; y la agresividad de los animales que desempeñan el papel de narradores a lo largo de la historia. A través de esta obra autoficcional, Mouawad crea un relato donde las fronteras

sont abordées pour être remises en discussion. Qu'il s'agisse des frontières spatiales ou temporelles, des frontières définies par l'homme mais qui n'ont pas la même valeur pour tous les hommes, ou de la présence d'un côté obscur en lui qui ne peut être marginalisé, ou des frontières tracées, marquées sur le corps, aucune ne saurait se résoudre, en définitive, à un sens univoque. (Cubeddu-Proux, 2016: 178)

Mouawad va más allá de los límites simbólicos, es decir, cada frontera evoca un concepto o una idea que Wajdi Mouawad quiere franquear o incluso romper. Nuestro principal objetivo es demostrar cómo nuestro autor cuestiona y excede los límites preestablecidos con el fin de retratar la verdadera identidad de un alma atormentada por la crueldad y la violencia desmedida de la Guerra Civil libanesa. Este análisis no sólo aborda la identidad del protagonista, sino también la identidad del individuo exiliado, excluido de su propio país y privado de su cultura, su lengua y la familiaridad de su vida pasada (Said, 2001). Para llevar a cabo este estudio, examinaremos Anima explorando y estudiando en profundidad las fronteras lingüísticas, espacio-temporales, sexuales, psicológicas y humanas abordadas a lo largo de la novela. Estas nos permitirán adentrarnos en la personalidad e la identidad del protagonista. 
En un primer momento, expondremos en la frontera lingüística la función que cumplen la pluralidad de lenguas y el elenco de animales narradores en la construcción de la personalidad de Wahhch Debch. En segundo lugar, la geografía y la historia abordadas en Anima nos desvelarán, por un lado, la auténtica naturaleza del protagonista, y por otro, varias marcas de digresión espacio-temporal. A continuación, en las fronteras sexuales y psicológicas observaremos cómo la violencia infligida por el hombre provocará psicopatologías irreversibles en el protagonista. Seguidamente, la frontera humana nos desvelará la auténtica naturaleza del ser humano cuestionando así el origen de la violencia, la moralidad y la deshumanización de nuestra especie.

\section{Fronteras lingüísticas}

Anima se caracteriza por dos rasgos lingüísticos presentes en toda la novela, a saber, el multilingüismo y las voces narradoras de los animales.

La obra en cuestión se compone de diálogos, palabras sueltas y canciones en varios idiomas. Sin embargo, ninguno de ellos es elegido al azar por el autor. Así pues, encontramos que el francés comprende la lengua principal dado que se emplea para narrar la historia. No obstante, los personajes canadienses entremezclan este idioma con el inglés, como observamos en este fragmento: “-I'm busy. Can't spend time with you. Viens, Wahhch" (Mouawad, 2012: 102). El quebequense, también presente en los diálogos, es el francés utilizado en la provincia de Quebec y se caracteriza por neologismos como "caller un taxi" (ibid.: 56) y "char" (ibid.: 53) traducido como "voiture” en francés estándar. El árabe libanés corresponde a la lengua materna del protagonista y, por lo tanto, también aparece en ciertas conversaciones y monólogos: "Il y avait un couple... Un couple... As'ab chi houwwé e-ttôkhbîr Ma fi as'ab menno... Tu comprends?” (ibid.: 439). Otras lenguas también representadas en esta narración comprenden el amerindio, la lengua de la reserva y de la comunidad del asesino; y el latín utilizado para escribir los nombres científicos de los animales. Este último es utilizado por Mouawad en la traducción del título de la obra, Anima, dado su doble significado: "souffle, souffle vital, âme" y "créature, être animé, personne", como explica Gaffiot (Montel-Hurlin, 2016: 205). Estas dos interpretaciones alertan al lector sobre la polifonía narrativa compuesta por animales que se introducen con sus nombres científicos en latín, así como sobre la búsqueda de la identidad de Wahhch Debch, que se encuentra "dans la déambulation spatiale de ce souffle, de cette âme, de cette vie qui se cherche" (ibid.: 205).

A diferencia de los seres humanos quienes se comunican en las lenguas estudiadas anteriormente, los animales sólo emplean el francés estándar para describir sus acciones, sentimientos y lo que perciben a través de sus sentidos. Esta lengua permite a los animales no sólo la narración de los sucesos que acontecen durante el viaje de Wahhch Debch, sino también la capacidad de traducir, ya que cuando el protagonista se encuentra en los Estados 
Unidos, nos informan en francés de los diálogos de los humanos que hablan en inglés. En Anima el francés se convierte en una lengua de intercambio y de comunicación entre el lector y el escritor (Delbart, 2005: 222).

Por otro lado, el plurilingüismo podría producir "un effet-pluriel, voire un effet-Babel" (Achard-Bayle \& Mansour, 2016: 71), es decir, la comprensión del lector podría verse afectada. Sin embargo, a pesar de no conocer alguno de los idiomas que conforman este mosaico lingüístico, la obra sigue siendo inteligible: "le français, l'anglais [...] utilisés sans traduction dans le texte, mais insérés naturellement dans les dialogues, les frontières linguistiques tombent." (Cubeddu-Proux, 2016: 179). Édouard Glissant (1996: 27) considera que una obra literaria monolingüe provoca "la pensé linéaire" del lector. En otras palabras, limita nuestra aprehensión con lenguas extranjeras y, por lo tanto, nuestra concepción del mundo. Afirma que el objetivo no es escribir en varios idiomas, sino mostrar su presencia. En este caso, Mouawad demuestra que la comprensión de un texto en varios idiomas sin que el lector los domine es posible. Asimismo, enriquece el discurso y descarta la hegemonía lingüística gracias a la representación de dialectos e idiomas en peligro de extinción como el amerindio.

En lo que concierne la comunicación entre diferentes seres vivos, hay que señalar que no siempre se limita a la expresión oral. Muchas especies animales e incluso vegetales utilizan signos, sonidos, danzas o cambios químicos para transmitir un mensaje. Un ejemplo serían las investigaciones del etnólogo von Frisch (1984) donde revela que la danza en círculos o en "ocho" de las abejas muestra la ubicación y la calidad del polen encontrado. Al igual que esta especie, los humanos y los animales también son capaces de comunicarse sin el uso del lenguaje:

Qu'est-ce autre chose que parler, cette faculté que nous leur voyons de se plaindre, de se resjouyr, de s'entr'appeler au secours, se convier à l'amour, comme ils font par l'usage de leur voix? [...] elles parlent bien à nous, et nous à elles. En combien de sortes parlons nous à nos chiens? et ils nous respondent. (Montaigne citado por Derrida, 2006: 21)

Montaigne considera que la comunicación entre las diferentes especies no está condicionada por el uso del lenguaje, sino por la empatía. En otras palabras, a diferencia de algunos humanos, los animales se identifican con el dolor y el sufrimiento de Wahhch Debch. Tomemos de ejemplo de la reflexión del cerdo mientras observa al protagonista: "Il n'est pourtant pas de ma race et je ne suis pourtant pas de la sienne, mais par la grâce de je ne sais quelle magie, je suis devenue lui et je crois qu'il est devenu moi." (Mouawad, 2012: 186).

Mouawad confisca la palabra de los hombres para dársela a los animales. Estas criaturas cumplen su función de narrar lo indescriptible. Desde el comienzo de la obra se presenta la traumática escena de Wahhch Debch descubriendo a su esposa embarazada violada 
y asesinada. Por ello, el autor aborda "le point de vue du silencieux, de celui qui n'a pas la parole. [...] L'exclu pouvait comprendre cet homme qui venait d'être exclu brutalement de sa vie par la monstruosité de ce qu'il vient de vivre" (Bourseiller, 2012: en línea). En otras palabras, todas las criaturas que participan en la historia tienen la capacidad del lenguaje, ya que representan en cierto modo a Wahhch Debch que acaba de ser excluido de la familiaridad de su vida cotidiana y de la realidad que conocía.

Como resultado, nuestro protagonista se excluye del mundo que le rodea para hacer frente a la violencia y el trauma sufridos en el pasado. Por consiguiente, se les otorga la palabra a los animales, es decir, aquellos que han sido silenciados pueden empatizar con Wahhch Debch y ejercer el papel de narradores y traductores: "L'animal dans le roman est une figure du tragique parce qu'il est une figure silencieuse, isolé de l'homme, témoin impuissant d'une noirceur que le dépasse" (Alix, 2016: 118). A través de la pluralidad de las lenguas y la multiplicidad de narradores Mouawad logra transcender las fronteras lingüísticas.

\section{Fronteras espacio-temporales}

A lo largo de la novela, Mouawad hace numerosas alusiones a la mitología y la literatura. Es el caso de La Divina Comedia de Dante (1987) ya que al igual que Dante, al principio de Anima el protagonista se encuentra en las puertas del Infierno cuando descubre el cadáver violado de su esposa. Esta analogía la encontramos en la Canción III de la obra italiana:

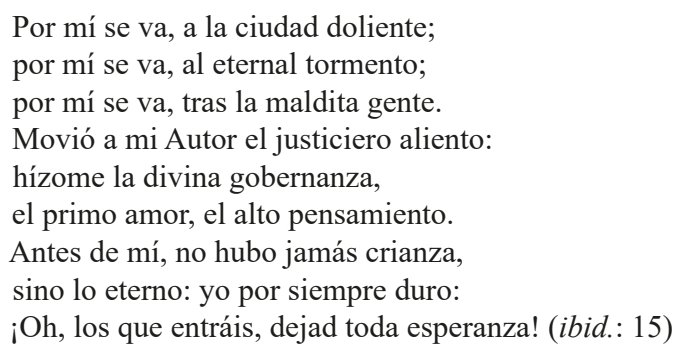

Esta odisea comienza tan pronto como Wahhch Debch cruza el puente, lugar donde inicia su búsqueda, para entrar en la Reserva india de Kahnawake y se pierde en el bosque al igual que en La Divina Comedia: "J'ai traversé le pont et je me suis perdu" (Mouawad, 2012: 52). Mientras que Dante desciende los nueve círculos concéntricos que componen el Infierno hasta encontrarse con Lucifer, Wahhch Debch elegirá el mismo camino con el fin de descubrir sus auténticas raíces. En este fragmento de Anima, Welson Wolf Rooney viola a Debch y le dice: "Maintenant! Ça va être les ténèbres dans ton ventre! Tu sens les ténèbres? Prends! Passe par les ténèbres, tu trouveras la lumière!" (ibid.: 311). En este mensaje Mouawad compara la oscuridad de las tinieblas con la 
pendiente del protagonista hacia el Infierno y la luz con el fin de su odisea, es decir, el descubrimiento de sus orígenes. Dante y Debch no son los únicos en descender a este Infierno. El propio lector también se adentra en este abismo experimentando los mismos horrores que sufre el protagonista.

Otro guiño que hace el escritor a La Divina Comedia lo encontramos en la ciudad de Virgilio (Kansas) donde Debch conoce a Winona. Este personaje representa en este contexto a Caronte, el primer guardián del Infierno, que ayuda a Dante a cruzar en su barca el Aqueronte, el río infernal donde vagan las almas que desean llegar a la otra orilla: "Toutes les âmes ont besoin d'un passeur, Charon en sa barque, pour atteindre les rives brûlées de l'enfer, tu [Winona] es mon passeur en ton pick-up, petite fée, et oui fuyant Virgil, et demain quittant Ulysses, il nous faudra le poète l'a dit, laisser ici toute espérance" (ibid.: 412). Este fragmento forma parte de una conversación entre Debch y Winona en Ulises, Kansas. La elección de la ciudad tampoco es arbitraria, ya que alude al pecado de Ulises. Este héroe mitológico se encuentra en el malebolge o el Octavo círculo del Infierno. En este foso se castiga a los estafadores, ya que su delito es "avoir franchi les 'frontières' du monde connu à son époque" (Cubeddu-Proux, 2016: 164). En otras palabras, Ulises está atrapado en el Infierno por su descontrolada sed de conocimiento durante la Guerra de Troya. Al igual que este héroe de la mitología griega, Debch busca la verdad sobre sus orígenes excediendo cualquier límite preestablecido.

Por otro lado, el protagonista viaja sin pasaporte y sin permisos especiales por Estados Unidos y Canadá. Wahhch Debch comienza su odisea en Montreal y termina en Animas, un pequeño pueblo de Nuevo México. Este lugar donde finaliza al relato hace alusión al título de la novela. Anima no sólo se refiere a la polifonía narrativa animal, sino también a su significado en latín: alma. De hecho, se podría decir que en Animas Debch pierde su alma por el atroz asesinato de su padre adoptivo: “-Wahhch, où vas tu?- Faire le sacrifice de mon âme" (Mouawad, 2012: 466); "Wahhch Debch m'avait fait venir à Animas pour que je sois témoin de la mort de son propre père dont il avait dû attacher les mains pour l'empêcher de se défendre" (ibid.: 491).

En la tercera parte de la novela, Mouawad nombra los capítulos con ciudades situadas en los Estados Unidos. Esta elección de topónimos no es insignificante, ya que esta cartografía hace referencia ya sea a un territorio extranjero, o a un mito para acercarse al Mediterráneo y al Oriente Medio. Algunos ejemplos son el Líbano (Illinois), la carretera de Jerusalén (Illinois), Tebas (Illinois), El Cairo (Illinois), Orán (Missouri), El Dorado (Kansas), Atenas (Kansas), Virgilio (Kansas) y Ulises (Kansas). Para desorientar aún más al lector, el autor omite cualquier descripción de las ciudades que atraviesa nuestro protagonista. Esto permite un desplazamiento espacial, es decir, podemos imaginarnos estar en Oriente y Occidente al mismo tiempo. Tomemos el ejemplo de Cartago en la obra esta ciudad está situada en Missouri, pero también corresponde con una de las más antiguas fundaciones coloniales fenicias situadas en el norte de África que data de finales del siglo IX a.C. De esta manera, se produce 
"l'étendue", un concepto creado por Glissant (1990) a través del cual coexisten varias líneas temporales y espaciales.

La relevancia del capítulo "Cartago" no pasa desapercibida dado que simboliza un puente que une dos culturas y dos países diferentes, a saber, la Guerra de Sucesión representada teatralmente por sus ciudadanos y el genocidio de Sabra y Chatila que aparece en las fotografías. El primero de los acontecimientos históricos que aparecen en Cartago comprende la Guerra de Sucesión de los Estados Unidos. De 1861 a 1865 una confederación de estados del norte, formada por trabajadores industriales y proteccionistas y dirigida por Abraham Lincoln, luchó contra una confederación de estados del sur, compuesta por propietarios de esclavos y comerciantes libres y dirigida por Jefferson Davis. Este conflicto ocurrió debido a la Cuestión Negra, ya que Lincoln se oponía estrictamente a la esclavitud. El segundo acontecimiento histórico comprende la Guerra del Líbano la cual tuvo lugar del 16 al 18 de septiembre de 1982. Se la considera una de las mayores masacres de la historia de la humanidad debido a los numerosos refugiados palestinos asesinados y torturados por las milicias cristianas en Beirut. Esta masacre se produjo como venganza por el asesinato del jefe de las Fuerzas Libanesas y recién elegido presidente, Bashir Gemayel, el 14 de septiembre de 1982.

A pesar de que estos dos acontecimientos históricos tienen su origen en lugares tan alejados espacialmente, el Líbano y los Estados Unidos, y temporalmente, mediados del siglo XIX y finales del siglo XX, ambos se superponen en el mismo espacio (Yocaris, 2016: 148). La desorientación a la que nos expone Mouawad provoca la superposición de episodios históricos, es decir, el lector percibe que la Guerra de Sucesión ha estallado en Sabra y Chatila: “en dépit de tout ce qui peut les éloigner dans l'espace et dans le temps, ces guerres semblent entrer en dialogue les unes avec les autres autour d'une même frontière symbolique" (Cubbedu-Proux, 2016: 176). Asimismo, se desenmascaran los orígenes palestinos del protagonista. Como resultado, Wahhch Debch personifica el vínculo entre Oriente y Occidente: un individuo que nació en Palestina y residió en Canadá.

Esta desterritorialización discursiva cuestiona al mismo tiempo la identidad del extranjero por lo que cabe preguntarnos: ¿la migración, ya sea voluntaria o forzada, construye nuevas identidades móviles o priva al individuo de una identidad y provoca la búsqueda de la misma? En términos de Hiernaux-Nicolas (2005: 14-15), a pesar de las circunstancias negativas que obligan a los migrantes a abandonar su país, la migración fomenta el intercambio cultural en el país de acogida. Por ello, "la ausencia de continuidad espacio-temporal [...] reflejan un abordaje distinto, dirigidos hacia la constitución de modelos identitarios innovadores y voluntaristas para asumir una pertenencia cualquiera”. Sin embargo, según Heidegger (2015), la identidad del individuo se configura a través de su relación con el espacio que le rodea. En el caso de los refugiados, exiliados e inmigrantes que abandonan su país por causas ajenas a ellos, su relación con su país natal queda nublada por recuerdos negativos, y 
en ocasiones traumatizantes. Tanto la guerra de Sucesión en Estados Unidos como la masacre de Sabra y Chatila dejan huella en el paisaje, en las personas y en su vida cotidiana. A menudo los recuerdos traumáticos que provocan dichos periodos bélicos reemplazan la auténtica identidad del país:

C'est fou comme un pays en guerre perd son identité, sa "réalité" se réduisant à quelques images, toujours les mêmes: tanks, soldats, explosions, camions en flammes, femmes éperdues criant devant la caméra et, de temps en temps, "l'homme de la rue" interviewé entre deux bombardements, qui dit en quelques mots sa colère ou son désarroi. (Fréchette, 2005: 119)

En Anima esta idea se refleja en los orígenes palestinos de Wahhch Debch, es decir, en lugar de rememorar la cultura, las tradiciones, la gastronomía, los paisajes y la gente de su país de origen, sólo retiene infaustos recuerdos de su infancia causados por los horrores de la guerra. Aquellos que logran sobrevivir deben comenzar una nueva vida. Sin embargo, quedan marcados por las atrocidades presenciadas y quedan atrapados en las férreas y ácidas visiones de lo que fue su realidad en el pasado. A menudo estas víctimas deben exiliarse en un país extranjero, como es el caso de Mouawad. No obstante, la identidad de los exiliados no se construye en el país de origen, sino al contrario, en el país de acogida. Es lo que le ocurre a Debch cuando se reúne con otros libaneses: "Voilà ce que la guerre a fait de nous. Nous sommes Libanais tous les trois et nous n'arrivons pas à nous parler" (Mouawad, 2012: 448). A pesar de haber nacido en el mismo país, su identidad pertenece al país donde se exilian.

Finalmente, Anima logra franquear los límites del espacio-tiempo gracias a una toponimia meticulosamente seleccionada por el autor. Como resultado, se crea un puente que unifica a Oriente y Occidente a través de la cultura, la mitología y la historia. Esto permite rememorar los recuerdos bloqueados de su infancia y descubrir la verdad de su pasado y su auténtica naturaleza.

\section{Fronteras sexuales y psicológicas}

Como hemos comprobado a lo largo de este artículo, Anima se caracteriza por una agresividad descontrolada: violaciones, genocidios, torturas, asesinatos y guerras. Por ello, la manera en la que se aborda la sexualidad de los personajes no es una excepción. En este fragmento, el gato nos describe el cuerpo del asesino Welson Wolf Rooney y los animales tatuados en su piel, retratándolo como un objeto de deseo:

Il est sorti de ses vêtements comme un animal sauvage sort de sa tanière dans tout l'éclat de la puissance. Un félin sublime de bestialité. [...] C'était, en soi, une vision, un paysage, d'autant plus surprenant que le tatouage [...] Oiseaux, fauves et animaux marins, aux couleurs chatoyantes, au regard agressif, perchés à la saillie des 
omoplates, tapis à la frontière des épaules, glissant le long de la colonne vertébrale ou émergeant depuis les côtes, couvraient toute la surface de son dos. La poitrine, domaine privilégié des chauves-souris dont l'essaim surgissait des ténèbres d'un nombril cerclé de noir, était opaque comme une plaque de nuit. Une ornementation effroyable d'insectes tapissait ses longues jambes massives [...] Blattes, vers, scarabées, libellules [...] se perdaient dans la raie des fesses. [...] Le sexe, seul, vierge de tout tatouage, proéminent, pendait entre les jambes, violacé et rougeâtre à son extrémité. À la jonction de toutes les bêtes, il se révélait être un objet de convoitise. (Mouawad, 2012: 304-305)

El felino define sus movimientos como elegantes y sensuales y compara su musculatura con la suya propia. Welson Wolf Rooney deviene su igual: un animal salvaje e indomable. Nuestro narrador nos detalla cada ser vivo que adorna su piel y cubre su cuerpo a excepción de su sexo, impoluto de cualquier rastro de tinta, atrayendo así su atención y la del lector. En esta escena el agresor nos desvela su identidad y el motivo que le empuja a llevar tan brutales violaciones:

- Quand un mâle termite rencontre une femelle termite, le mâle cherche à se mettre dans le trou de la femelle. Sauf que le trou, le termite, il le cherche pas, tu comprends? Il a pas le temps, ça l'intéresse pas de chercher [...] Avec ses crocs, il poignarde le thorax de sa femelle puis il la baise dans la plaie [...] Est-ce que tu es une femelle? [...]

- Non!!

- C'est une chance parce que moi je suis un termite. (ibid.: 308-309)

La naturaleza de Wolf Rooney se muestra cruel, bestial y descontrolada imitando así el comportamiento de la termita macho. Asimismo, existe una reflexión meta-textual que relaciona la tinta de los tatuajes inyectada en la piel con el semen introducido en el vientre de Léonie. Ambos penetran de manera implacable y ruda, al igual que el lector cuando lee las primeras páginas de Anima con la desgarradora imagen del cadáver violado de una mujer embarazada. Por consiguiente, es irrebatible afirmar que la sexualidad y la violencia constituyen el leitmotiv de la obra.

Esta atmósfera de amenaza y ansiedad originan varias psicopatologías en el protagonista. Según Freud, dada la represión de su propia existencia después de una experiencia traumática, el sujeto manifiesta un desdoblamiento de su ser: "le phénomène du double dans toutes ses gradations et extensions [...] -donc dédoublement du moi, division du moi, permutation des "moi"-; et enfin le constat retour du même" (Aubry, 2016: 255). La identidad de Wahhch Debch se ve alterada debido al homicidio de su mujer. Esto provoca que desconfíe de sí mismo y de su inocencia, es decir, nuestro protagonista confiesa al forense que cree ser el responsable de este cruento acontecimiento: 
J'ai l'impression que ce n'est plus de moi qu'il s'agit, comme si la réalité avait perdu de son adhérence, de sa colle. Je veux dire par là que je commence à douter. [...] et c'est terrible parce que pendant une seconde, une seconde plus vite que c'est ma pensée, je me dis que c'est moi qui l'a tuée, c'est moi l'assassin et c'est pour cette raison que vous ne l'avez pas encore arrêté, c'est moi qui ai planté et planté et replanté et replanté encore le couteau dans son ventre avant d'éjaculer dans la plaie, alors je m'assois sur le lit et j'attends que ça passe, mais ça ne passe pas parce que tout ça me paraît possible, me paraît plausible, voilà pourquoi, si vous me montriez un visage en me disant. Voici celui qui a fait ça, il y a une chance que j'y découvre quelque chose qui saura me convaincre que ce n'est en effet pas moi qui l'a tuée. (Mouawad, 2012: 44)

Para comprender la incertidumbre de Debch y su deseo de desvelar el rostro del asesino, conviene examinar su inconsciente y su pasado (Fanon, 2002; Briole, 2018). Nuestro protagonista creció y se educó en Canadá, empero, sus orígenes nos revelan una realidad diferente. Así pues, el asesinato de su mujer desbloquea los recuerdos de su infancia durante la masacre de Sabra y Chatila, a saber, toda su familia fue asesinada y torturada. Sin embargo, la visión más tormentosa fue la de su hermana quien compartió el mismo destino que Léonie. El inconsciente, en términos de Freud (1925), es la reserva de deseos internos reprimidos e impulsos irracionales. Comprende el origen oculto que define nuestras motivaciones y esculpe nuestra identidad. Igualmente, argumenta que nuestros deseos reprimidos no sólo se revelan en nuestros sueños, sino que también penetran en nuestra existencia. Así pues, los recuerdos traumáticos de su infancia producen deformaciones del carácter lo que influye en la construcción de su personalidad y de su identidad. Estos instintos inhibidos no se reprimen cuando tienen la posibilidad de asegurar su satisfacción (Freud, 1968: 14).

En el caso de Debch los acontecimientos durante su infancia y su vida adulta engendran en él un complejo de Edipo sin resolver que le llevará a compartir el trágico destino del personaje griego: arrebatarle la vida a su padre. Esta psicopatología nace de dos hechos claves: 1) los feminicidios de Janice, Léonie y la hermana de Debch que desencadenan una percepción negativa del coito; y 2) la ausencia de una figura materna que provoca una relación tabú con su padre adoptivo.

Le personnage se crée donc un double qui le représente en violeur et meurtrier de la mère. [...] Wajdi Mouawad élabore ainsi à travers le roman un conflit dont le contenu simple nous est donné sous forme de fantasmes (scène primitive, matricide, parricide). La mise en acte de solutions défensives est également perceptible: projection et totémisme, clivage du héros, recherche d'un double. Tous les éléments du complexe d'EEdipe y sont. Le meurtrier qu'il faut retrouver pour s'en différencier devient le père qu'il faut tuer. (Aubry, 2016: 257-258)

Por consiguiente, es evidente que el protagonista desempeña el papel de víctima y asesino simultáneamente. Incapaz de escapar del parricidio como Edipo, su destino es 
revelado al lector arabófono ya que su nombre y su apellido significan monstruoso y brutal respectivamente: “Wahhch signifie plutôt Monstrueux. C'est un prénom d'autant plus étrange que Debch signifie Brutal..." (Mouawad, 2012: 423). Asimismo, Jaques Lacan (1950) sugiere que para que un castigo cobre sentido es necesaria la aprobación del crimen por la ley. Por ello, Debch invita al forense Aubert Chagnon a descubrir el cadáver de su padre para que su muerte adquiera una significación y no se convierta en un simple acto de venganza personal.

El asesinato y la tortura de su familia y su mujer embarazada desbloquean los recuerdos de su traumática infancia abriendo una herida en su mente y su alma tan desgarradora como la cuchillada en el vientre de Léonie que encuentra el protagonista y el lector al comienzo de la novela. El erotismo y la sexualidad quedan corrompidos en la narración de Mouawad excediendo los límites imaginados y desencadenando psicopatologías como el desdoblamiento del ser. Todos estos sucesos transforman la personalidad y el carácter de nuestro protagonista quien acaba asesinando su propio padre.

\section{Fronteras humanas}

Al finalizar nuestra lectura de Anima constatamos que se divide en cuatro bloques donde se suceden las diferentes voces narradoras, a saber: Bestiae verae, Bestiae fabulosae, Canis lupus lupus y Homo sapiens sapiens. Los dos primeros capítulos lo componen un elenco de especies divididas entre animales domésticos (Bestiae verae) y animales salvajes (Bestiae fabulosae) donde aparecen animales como un gato, una luciérnaga, una trucha y un coyote. El tercero, llamado Canis lupus lupus, es narrado por Mason-Dixon Line, un lobo cuyo único objetivo es la protección de su amo, Wahhch Debch. El capítulo final culmina con el depredador más peligroso de todos: el ser humano (Homo sapiens sapiens) interpretado por el doctor forense Aubert Chagnon. El orden de aparición de los narradores no es arbitrario. La agresividad y la crueldad se desatan a medida que avanza la novela. Mazboudi distingue así tres tipos de violencia entre diferentes especies y entre sus iguales: "la violence de l'animal envers l'animal, la violence de l'homme envers l'animal et de l'animal envers l'homme et enfin la violence de l'homme vis-à-vis de l'homme" (Mazboudi, 2016: 270).

En primer lugar, encontramos la violencia entre animales justificada por su instinto de supervivencia, es decir, por la necesidad de defenderse y/o alimentarse. Tomemos estos dos ejemplos de una araña comiendo un mosquito: "Un insecte, attiré par la lumière devant laquelle j'avais tissé ma toile, a été pris au piège. [...] Petit moucheron dont j'ai dévoré la tête sans me donner la peine d'emmailloter son corps" (Mouawad, 2012: 69); y de una boa constrictor mientras devoraba un ratón vivo: “Je me suis penché vers lui. Il m’a vu, il a voulu fuir, mais je l'avais déjà happé par la tête, enfonçant légèrement mes dents dans la chair de son 
cou pour l'immobiliser. [...] C'était une délice" (ibid.: 97). Ambos depredadores se deleitan con el sufrimiento de su presa, juegan y disfrutan torturando y comiéndose a su víctima sin sentir empatía o lástima por la otra especie. En lo que respecta a los animales, el instinto de supervivencia les impulsa a matar y por lo tanto no simpatizan con el dolor de sus presas. Es la ley del más fuerte la que rige el comportamiento de los animales.

En segundo lugar, observamos la violencia entre el Hombre y la bestia. En Anima, guardan una relación metonímica, dado su "dispositif totémique propre à la tradition amérindienne" (Badiou-Monferran, 2016: 18). Según la filosofía amerindia, a cada ser humano se le asocia con un tótem animal que lo identifica. En el caso de los Ojibwe, la grulla representa su tótem:

- Sais-tu quel est le totem le plus influent chez les Ojibwés?

- Non.

- La grue. Comme celle que tu nous as apportée. [...] Teha'no htetsihs en langue wendat.

[...] On t'a vu au bout de la route et je me suis dit que c'était le grand esprit en personne qui débarquait chez nous avec le miroir de nos Nations dans les bras: meurtries mais vivantes. (Mouawad, 2012: 189)

Cada personaje es emparejado con un animal: el anciano y la serpiente Jesús, Janice y el gato, Coach y el mono Tomahawk, Chuck y su perro Motherfucker. Todos demuestran cualidades de lealtad, confianza, devoción y apego. A esta lista incluimos a Wahhch Debch y Mason-Dixon Line. Éste último comprende la reencarnación de Welson Wolf Rooney cuyo nombre ya previene al lector de su tótem a través de la traducción inglesa de "wolf", es decir, "lobo":

\begin{abstract}
Rooney est mort... Je crois qu'il est mort... j'ai pris mon couteau et je l'ai planté dans sa gorge [...] j'ai perdu connaissance. Quand j'ai ouvert les yeux, à la place il y avait ce chien... ce chien énorme... comme si Rooney était devenu ce chien, sa vraie nature... chien sauvage. J'ai pensé à ce que m'avait dit un vieil homme à propos de celui qui tue son propre totem: Tout se confond. Mais ce chien semble né de la puissance de Rooney. Animal il me protège quand humain il a voulu me détruire. Je crois que c'est lui qui a arrêté le saignement de mon visage, qui m'a sorti de la rivière. Sans lui, je crois bien que je serais mort. Depuis, il me suit et ne me quitte plus. (Mouawad, 2012: 344-345)
\end{abstract}

Sin embargo, al igual que los dos hombres ligados a este tótem, Mason-Dixon Line concibe dos naturalezas: por un lado, el Canis lupus familiaris o perro, amigo del hombre, su acompañante más fiel, su guía y protector; y, por otro lado, el Canis lupus lupus o lobo, un ser más salvaje e impredecible, insensible e indiferente con respecto al sufrimiento de su víctima. Este canino representa las dos caras de una misma moneda: amigo y enemigo. Wahhch Debch toma a su perro entre sus brazos y llora cuando recuerda haber sido enterrado vivo junto a las cabezas de los caballos siendo un bebé después de que asesinaran y torturaran a su familia. Este sin poder consolarlo con palabras, le ofrece su silencio: 
Sa peine est devenu ma peine. Un gouffre me sépare de la parole. Comment consoler à un humain. Je lui offre mon silence, tiens, il est à toi, écoute-le et dis-moi qui devraisje dévorer, quel mal, quelle peine. [...] J'aurais voulu être là il y a longtemps pour te défendre $[\ldots]$ mais je n'étais pas là, pas encore. (Mouawad, 2012: 372)

En esta escena, los amargos y traumáticos recuerdos de la guerra que hacen sufrir al protagonista son originados por el ser humano, empero, es consolado por un animal. ¿Quién es entonces la bestia? Mouawad utiliza un registro irónico, pero también paradójico: la bestia que no es la bestia y el humano que no es humano. El autor juega con esta ambigüedad cuando las características de los animales se atribuyen a los humanos y viceversa. Aquí rompemos una frontera entre el animal y el ser humano al conferirle cualidades que normalmente atribuimos a las personas como la empatía, la compasión, la simpatía y el respeto.

En tercer y último lugar, analizamos la violencia entre seres humanos. A lo largo de este análisis hemos sido testigos de la brutalidad y la agresividad descritas. Nos referimos a violaciones, torturas y asesinatos sin distinción de sexo o edad: hombres, mujeres, ancianos, niños y recién nacidos. En este contexto, Wahhch Debch representa la dualidad del bien y del mal ya que encarna a la víctima y al asesino cuando mata a Rooney y a su padre para protegerse y vengarse. Esto nos lleva a una pregunta fundamental del pensamiento humano: ¿puede justificarse la violencia? A lo largo de la historia, varios filósofos han concebido la moral de dos maneras diferentes: o bien se deja influenciar por factores externos, como la religión, la política e incluso la sociedad o bien el hombre construye su propia moral. Sartre encarna uno de los pensadores que defienden esta noción afirmando que el ser humano es responsable de sus acciones y decisiones: 'L'homme n'est rien d'autre que l'ensemble de ses actes [...] Un homme s'engage dans sa vie, dessine sa figure, et en dehors de cette figure, il n'y a rien [...] le lâche se fait lâche, le héros se fait héros" (Sartre, 1996: 51-55). Sartre define al individuo como un ser libre que posee la capacidad consciente de elegir lo que desea llegar a ser (Sartre, 1943). Por consiguiente, todas nuestras decisiones son tomadas conscientemente por nosotros.

Desde esta óptica, encontramos el caso de Welson Wolf Rooney quien mata por satisfacer su deseo e interés personal ignorando las consecuencias de sus actos. La empatía y la responsabilidad quedan así anulados. No obstante, en términos de Sartre, es imprescindible que el ser humano sea consciente de la repercusión de su decisión en el resto de la humanidad.

On doit toujours se demander: qu'arriverait-il si tout le monde en faisait autant? et on n'échappe à cette pensée inquiétante que par une sorte de mauvaise foi. Tout se passe comme si, pour tout homme, toute l'humanité avait les yeux fixés sur ce qu'il fait. Et chaque homme doit se dire: suis-je bien celui qui a le droit d'agir de telle sorte que l'humanité se règle sur mes actes? (Sartre, 1996: 34-36) 
Sin embargo, existen individuos que son conscientes de sus actos y aún así son capaces de infligir daño al prójimo. Esto se debe por varios motivos. Machiavelli (1866), por ejemplo, justifica la violencia de la guerra para proteger a su pueblo y ser más poderoso que su oponente. Esta idea de la guerra nos lleva a la siguiente pregunta: ¿cómo es posible que seres de la misma especie se maten entre sí? A diferencia de las bestias, los humanos son conscientes de sus acciones. Arendt explica que los conflictos armados no pertenecen a la naturaleza humana, aunque se producen debido a la falta de conciliación en las rivalidades causadas por el desacuerdo entre las diferentes naciones, religiones, razas, etc:

Si la guerre est encore présente, ce n'est pas qu'il se trouve au fond de l'espèce humaine une secrète aspiration à la mort, non plus qu'un irrépressible instinct d'agression, ce n'est même pas, ce qui serait plus plausible en fin de compte, le fait que le désarmement puisse présenter, d'un point de vue économique et social, de très sérieux inconvénients; cela provient tout simplement du fait qu'on n'a pas encore vu apparaître sur la scène politique d'instance capable de se substituer à cet arbitre suprême des conflits internationaux. (Arendt, 1997: 107)

La falta de empatía que capacita a un ser humano a matar a otro ser vivo es debido a la habituación, que implica un proceso por el cual un individuo sometido a un estímulo repetido termina acostumbrándose a él. La habituación provoca además la aparición de otros factores como la disociación. Este último comprende un mecanismo de defensa mental que usamos para separar nuestra conciencia y moral de nuestras acciones (González, 2010). En Anima el bloqueo de la empatía para llevar a cabo actos inefables se repite de manera frecuente a través de los homicidios, las violaciones, las torturas y las guerras de Estados Unidos y el Líbano. Las personas que participan en tan atroces actividades bloquean su empatía evitando así interactuar y sentir compasión por sus semejantes, de lo contrario nunca podrían cometer tales perjuicios. También es el caso del protagonista quien sufre síntomas disociativos como pueden ser "la amnesia, [...] despersonalización, desrealización, [y] flashback" (Mora Pérez, 2015: 35).

Esta violencia en sus múltiples facetas que no solo observamos en Anima, sino también en el mundo que nos rodea, nos hace cuestionarnos la racionalidad y la humanidad del ser humano. La relación del ser humano con el resto de su comunidad y con él mismo es clave para lograr un ambiente de paz y prosperidad (Ouellet, 2007). Sin embargo, es preciso no olvidar que "tras la pantalla de la civilización, que favorece la pacificación de la relación entre los hombres, nada cambia en cuanto a sus instintos fundamentales" (Briole, 2018: 9). 


\section{Conclusión}

A lo largo de este artículo hemos comprobado cómo Wajdi Mouawad retrata la vida atormentada de Wahhch Debch, un personaje desgarrado y traumatizado por la crueldad desenfrenada de sus recuerdos durante la masacre de Sabra y Chatila. Lugar en el que su padre adoptivo le separó de su familia para criarlo después de haberles asesinado, violado, despedazado, torturado y enterrado vivos. Lo que parece, al principio, una desesperada necesidad de vengar a su mujer embarazada asesinada y violada, acaba por convertirse en una búsqueda de sus raíces y, por lo tanto, de su identidad. Debch descubrirá la auténtica naturaleza del ser humano: impredecible, salvaje e impía.

En Anima el protagonista vive dos guerras diferentes: la guerra civil libanesa durante su infancia, y como consecuencia, una guerra interior que nace del exilio, el trauma y las heridas del pasado y desencadena una nueva búsqueda de la identidad. Mouawad expone en este relato sus experiencias y sentimientos originados del exilio ideológico, cultural, lingüístico y geográfico del que fue testigo durante su infancia debido a los conflictos civiles que asolaron el Líbano. El exilio, en términos de Adorno, deja siempre huella en la identidad de aquel que se ve infligido por esta huida dejando atrás todo lo que le es familiar:

Todo intelectual en el exilio, sin excepción, lleva una existencia mutilada [...] Vive en un entorno [...] incomprensible; [...] siempre está desorientado. [...] Su lengua queda desarraigada, y la dimensión histórica de la que su conocimiento extraía sus fuerzas allanada. [...] Aun el que está excluido del oprobio de la inmediata igualación con los demás lleva como su marca particular esa misma exclusión, que determina una existencia aparente e irreal dentro del proceso vital de la sociedad. (Adorno, 2004: 38)

A través de esta obra autoficcional, el escritor desempeña el papel de espectador comprometido, testigo ocular de los hechos y de pensador, permitiéndole reflexionar acerca de la identidad del exiliado apoyándose en sus experiencias de antaño y, por ende, de su identidad narrativa: "Esta relación circular en la que se fragua una identidad mediante la recepción del texto que uno, en cierto modo, es y ha producido permite que un sujeto se reconozca en la historia que cuenta sobre sí" (Ricœur, 1999: 24). Es en este contexto, y a modo de conclusión, podemos afirmar que la guerra y el exilio exponen este proceso de reconstrucción de la identidad y la memoria de los exiliados forzados a abandonar su país, su lengua, su cultura y su ser a la vez que permite reflexionar sobre la naturaleza y la moralidad del ser humano. 
Anales de Filología Francesa, n. ${ }^{\circ}$ 29, 2021

Marta Contreras PÉrez

\section{Referencias bibliográficas}

Achard-Bayle, Guy \& Léda Mansour. 2016. "Mise en fiction, texte et hors-texte dans Anima" in Badiou-Monferran, Claire \& Laurence Denooz (eds.). Langues d'Anima. Écriture et histoire contemporaine dans l'œeuvre de Wajdi Mouawad. Paris, Classique Garnier, 63-80.

Adorno, Theodor Ludwig. 2004. Minima Moralia. Madrid, Akal.

Alix, Florian. 2016. "Le tragique de la relation dans Anima" in BADIOU-Monferran, Claire \& Laurence Denooz (eds.). Langues d'Anima. Écriture et histoire contemporaine dans l'œuvre de Wajdi Mouawad. París, Classique Garnier, 115-129.

Arendt, Hannah. 1997. Du mensonge à la violence. Paris, Calmann-Lévy.

Arendt, Hannah. 2013. "Nous autres réfugiés" in Pouvoirs, n¹44, 5-16.

Aubry, Laurence. 2016. "Les langues d'Anima, voix romanesques et voies littéraires" in Badiou-Monferran, Claire \& Laurence Denooz (éds.). Langues d'Anima. Écriture et histoire contemporaine dans l'œuvre de Wajdi Mouawad. Paris, Classiques Garnier, 253-267.

Badiou-Monferran, Claire. 2016. "Introduction", in Badiou-Monferran, Claire \& Laurence DenOOZ (eds.). Langues d'Anima. Écriture et histoire contemporaine dans l'œuvre de Wajdi Mouawad. Paris, Classiques Garnier, 13-38.

Blarduni, Estela. 2015. "Teatro, historia y arte en Le Sang des promesses de Wajdi Mouawad" in Artal Maillie, Susana G. \& Francisco Aiello (eds.). Desarraigos: de la experiencia a la escritura: Estudios argentinos de literatura francesa y francófona. Batán, Letra Sudaca Ediciones, 21-28.

Bourseiller, Christophe. 2012. "Wajdi Mouawad La matinale 1810 12" in France Musique: <https://www.youtube.com/watch?v=i8VQ1AWGZ7A> [03/11/2020].

Briole, Guy. 2018. "El trauma de un pueblo. ¿Qué paz después de la guerra?” in Avances en psicología latinoamericana, vol. $36, \mathrm{n}^{\circ} 1,1-10$.

Cubbedu-Proux, Stefania. 2016. "Langues d'Anima et langue animale. Dialogue avec l'Amérique et l'Amérindien" in BADIOU-Monferran, Claire \& Laurence Denooz (eds.). Langues d'Anima. Écriture et histoire contemporaine dans l'œuvre de Wajdi Mouawad. Paris, Classique Garnier, 161-181.

Dante Alighieri, \& Bartolomé Mitre. 1987. La Divina Comedia. Buenos Aires, Jacobo Peuser.

Delbart, Anne-Rosine. 2005. Les exilés du langage: un siècle d'écrivains français venus d'ailleurs (1919-2000). Presses Universitaires de Limoges.

Deleuze, Gilles \& Félix Guattari. 1972. L’Anti-CEdipe. Paris, Éditions Minuit.

DerridA, Jacques. 2006. L'animal que donc je suis. Paris, Galilée.

FAnON, Frantz. 2002. Les damnés de la terre. Paris, Éditions La Découverte \& Syros. 
Anales de Filología Francesa, n. ${ }^{\circ}$ 29, 2021

Anima de Wajdi Mouawad: El trauma y la Violencia de la GUerRa en la CONSTRucción...

Fréchette, Carole. 2005. "Ma juste place” in Jeu, nº117, 119-123.

FreUd, Sigmund. 1925. Le rêve et son interprétation. Paris, Gallimard.

Freud, Sigmund. 1968. Essais de psychanalyse. Paris, Payot.

Glissant, Édouard. 1990. Poétique de la Relation. Paris, Gallimard.

GLISSANT, Édouard. 1996. Introduction à une poétique du divers. Paris, Gallimard.

GonzÁLez, Anabel. 2010. Trastornos disociativos. Madrid, Pléyades.

Heidegger, Martin, Luis Asín, Arturo Leyte \& Jesús Adrián. 2015. Construir Habitar Pensar = Bauen Wohnen Denken. Madrid, La Oficina.

HiernauX-Nicolas, Daniel. 2005. “¿Identidades móviles o movilidad sin identidad? El individuo moderno en transformación" in Revista de Geografia Norte Grande, n 34, 5-17.

LACAN, Jacques. 1950. Introduction théorique aux fonctions de la psychanalyse en criminologie Ecrits. Paris, Seuil.

Machiavelli, Niccolò. 1866. Le Prince de Nicolas Machiavel. Paris, Bureaux de la publication.

Mazboudi, Badia. 2016. "Violence dans Anima entre légitimité et hybridation" in BADIOUMonferran, Claire \& Laurence Denooz (eds.). Langues d'Anima. Ecriture et histoire contemporaine dans l'œuvre de Wajdi Mouawad. Paris, Classique Garnier, 269-283.

Montel-Hurlin, Élise. 2016. “Anima, l'animal sans elle” in Badiou-Monferran, Claire \& Laurence DENOOZ (eds.). Langues d'Anima. Écriture et histoire contemporaine dans l'œuvre de Wajdi Mouawad. Paris, Classiques Garnier, 205-214.

Mora PÉrez, Virginia. 2015. “Cuando llueve sobre mojado: consecuencias psicológicas en mujeres víctimas de violencia de género traumatizadas en la infancia" in Journal of Feminist, Gender and Woman Studies, n ${ }^{\circ} 2,33-38$.

Morin, Edgar. 1993. Terre-patrie. Paris, Seuil.

Mouawad, Wajdi. 1999. Littoral. Montréal, Babel, Lemeac/actes sud.

Mouawad, Wajdi. 2003. Incendies. Montréal, Babel, Lemeac/actes sud.

Mouawad, Wajdi. 2006. Forêts. Montréal, Babel, Lemeac/actes sud.

MouAwaD, Wajdi. 2009a. "Biographie de Wajdi Mouawad": <http://www.wajdimouawad.fr/ wajdi-mouawad/biographie> [06/11/2020].

Mouawad, Wajdi. 2009b. Ciels. Montréal, Babel, Lemeac/actes sud.

Mouawad, Wajdi. 2012. Anima. Montréal, Babel, Lemeac/actes sud.

Ouellet, Pierre. 2007. "Le principe d'altérité” in Ouellet, Pierre \& Simon Harel (éds.). Quel autre? L'altérité en question. Montreal, VLB Éditeur, 7-43. 
Reyes Tovar, Miriam. 2011. "Desterritorialización como forma de abordar el concepto de frontera y la identidad en la migración" in Revista Geográfica de América Central Número Especial EgAL, 1-13.

Ricceur, Paul. 1999. Historia y narratividad. Barcelona, Ediciones Paidós Ibérica.

SAID, Edward. 2001. Reflections on Exile. Harvard Univeristy Press.

SARTre, Jean-Paul. 1943. L'Être et le Néant. Gallimard, Folio/Essais.

SARTre, Jean-Paul. 1996. L'existentialisme est un humanisme. Paris, Gallimard, (coll. Folio/ Essais).

Todorov, Tveztan. 1996. L’homme dépaysé. Paris, Seuil.

Vicente, Alex. 2014. "El rey de la tragedia se llama Wajdi Mouawad”. España: El País $<$ https://elpais.com/cultura/2014/02/05/actualidad/1391606496_023643.html> [23/10/2020].

Von Frisch, Karl. 1984. Vie et moeurs des abeilles. Paris, Albin Michel, Bibliothèque Sciences.

Yocaris, Ilias. 2016. "Une poétique de l'interconnexion" in Badiou-Monferran, Claire \& Laurence Denooz (eds.). Langues d'Anima. Écriture et histoire contemporaine dans l'œuvre de Wajdi Mouawad. Paris, Classiques Garnier, 147-159. 
